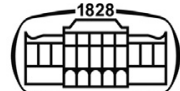

AKADÉMIAI KIADÓ

Journal of Behavioral Addictions

10 (2021) 2, 291-301

D01:

$10.1556 / 2006.2021 .00036$

(c) 2021 The Author(s)

\section{FULL-LENGTH REPORT}

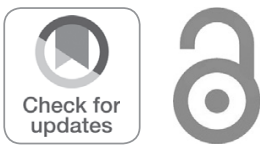

\title{
Social-networks-related stimuli interferes decision making under ambiguity: Interactions with cue-induced craving and problematic social-networks use
}

\author{
ELISA WEGMANN ${ }^{1}$, SILKE M. MÜLLER ${ }^{1,2}$, \\ PATRICK TROTZKE ${ }^{1,2,3}$ and MATTHIAS BRAND ${ }^{1,2 *} \odot$ \\ ${ }^{1}$ Department of General Psychology, Cognition and Center for Behavioral Addiction Research \\ (CeBAR), University of Duisburg-Essen, Duisburg, Germany \\ ${ }^{2}$ Erwin L. Hahn Institute for Magnetic Resonance Imaging, Essen, Germany \\ ${ }^{3}$ IU - International University of Applied Sciences, Erfurt, Germany
}

Received: July 15, 2020 • Revised manuscript received: January 26, 2021 • Accepted: May 15, 2021

Published online: July 5, 2021

\begin{abstract}
Background and aims: Social-networks-use disorder is discussed as a potential further type of disorders due to addictive behaviors. Theoretical models assume cue-induced craving and disadvantageous decision making to be relevant mechanisms. This study investigates if the presentation of social-networksrelated cues interferes with decision making under ambiguity. Methods: Craving was induced with a cue-reactivity paradigm and assessed with a visual analogue scale. Participants $(\mathrm{N}=146)$ played a modified Iowa Gambling Task with social-networks-related cues and neutral cues presented on the advantageous and disadvantageous decks respectively, or vice versa. Symptoms of social-networks-use disorder were measured with a modified version of the short Internet Addiction Test. Results: Overall, participants chose options with neutral cues more often than those with social-networks-related cues, even if it was disadvantageous. There was a significant interaction between decision-making performance and Iowa Gambling Task condition in predicting symptom severity. The results indicate that choosing decks with social-networks-related cues even if it was disadvantageous is associated with higher tendencies towards a social-networks-use disorder. The interaction with cue-induced craving did not explain further variance. Discussion and Conclusions: The results highlight the relevance of cue reactivity, decision making, and their interaction as potential mechanisms explaining tendencies towards a social-networks-use disorder. Decision making was influenced by affective responses, which could result in a higher risk of a potential addictive behavior. This is consistent with the findings from addiction research and with theoretical approaches assuming an imbalance between affective and cognitive processes in addictive behaviors.
\end{abstract}

\section{KEYWORDS}

problematic social networks use, SNS addiction, social-networks-use disorder, decision making, lowa gambling task

\section{INTRODUCTION}

Online communication applications and online social networks such as instant messenger services, social networking sites, and (micro-) blogs allow users to be connected, to communicate, and to share information, pictures, and videos (Boyd \& Ellison, 2007; Nadkarni \& Hofmann, 2012). Researchers discuss a problematic use of social networks and consider potential similarities with substance-use disorders and behavioral addictions such as gaming disorder (e.g., Andreassen et al., 2016). The problematic use of social networks also 
referred to as "social-networking-sites addiction" or "Facebook addiction" mainly describes the addiction-like usage of online social networks or communication applications, which is accompanied by the experience of negative consequences and loss of control (Andreassen, 2015; Kuss \& Griffiths, 2011, 2017; Wegmann, Mueller, Ostendorf, \& Brand, 2018). In contrast to gaming disorder, the problematic use of social networks is not recognized by the international classification systems of diseases such as the DSM-5 or ICD-11 (see American Psychiatric Association, 2013; World Health Organization, 2019). At present, there is a lack of consensus regarding the definition, description of symptoms, or terminology. Nevertheless, more researchers use the definition of gaming disorder as a basis to describe the problematic use of social networks. We prefer the umbrella term "social-networks-use disorder" or "problematic social-networks use" whereby the focus is on the problematic, addiction-like use of social networks in general and less on a single specific application or device, whereby the core symptoms and underlying psychological processes are derived from those of gaming disorder (Brand, Rumpf, Demetrovics, et al., 2020; Brand, Rumpf, King, et al., 2020; Wegmann, Mueller, et al., 2018).

\section{Theoretical considerations}

The I-PACE (Interaction of Person-Affect-CognitionExecution) model by Brand, Young, Laier, Wölfling, and Potenza (2016) and its updated version (Brand et al., 2019) illustrate the mechanisms and processes assumed to be relevant for the development and maintenance of addictive behaviors, potentially including social-networks-use disorder. The model outlines that predisposing variables and specific motives interact with cognitive and affective responses such as cue reactivity, craving, internet-related cognitive biases, and mood management as well as with executive functions and decision-making abilities. The interaction of affective and cognitive components (e.g., the confrontation with addiction-related cues leading to cue reactivity and craving, diminished executive functions, inhibitory control, decision making), which include rewardrelated learning and reinforcing processes, is assumed to result in a continuation of the behavior (e.g., use of social networks), despite negative consequences in everyday life (Brand et al., 2019). The I-PACE model integrates components of previous theoretical considerations, including cue reactivity and craving (Tiffany \& Wray, 2012) and dualprocess approaches (Bechara, 2005; Everitt \& Robbins, 2005, 2016). Craving describes the subjectively experienced need or urge to consume a drug or to show a specific behavior (Carter \& Tiffany, 1999; Sayette et al., 2000), whereas cue reactivity is associated with the subjective and physiological response to specific addiction-related stimuli (Drummond, 2001; Tiffany \& Wray, 2012). Cue reactivity and craving were shown to be relevant in addictive behaviors, for example gambling disorder, gaming disorder, and buyingshopping disorder (Starcke, Antons, Trotzke, \& Brand, 2018), and, specifically, in social-networks-use disorder or as the authors called "social networking sites addiction" (Leng et al., 2019; Wegmann, Stodt, \& Brand, 2018). Referring to dual-process approaches, emotionally driven craving responses are part of the impulsive processing system that interacts with cognitive control processes from the reflective system (Bechara, 2005; Volkow, Wang, Fowler, \& Tomasi, 2012). A hyperactivity of impulsive processes is assumed to result in decision-making biased towards seeking immediate reward and gratification despite possible negative consequences, which, in the long term, may result in risky, addiction-like behavior (Breiner, Stritzke, \& Lang, 1999; Wiers, Ames, Hofmann, Krank, \& Stacy, 2010). Dysfunctional decision-making behavior, reflecting this imbalance, is considered as risk factor for and a consequence of an addictive behavior (Bechara, 2005; Brand et al., 2019; Dong \& Potenza, 2014).

\section{Decision making in addictive behaviors}

Research differentiates two types of decision-making situations: ambiguity and (objective) risk. Decisions under objective risk provide explicit information about probabilities and potential outcomes (Brand, Labudda, \& Markowitsch, 2006; Schiebener \& Brand, 2015). Decisions under ambiguity do not provide a-priori information about probabilities, consequences, and potential outcomes, and are associated with feedback processing, affective components, and implicit learning (Bechara, Damasio, \& Damasio, 2000; Damasio, 1994, 2004). Decision-making under ambiguity is most commonly assessed with the Iowa Gambling Task (IGT; Bechara, Damasio, Damasio, \& Anderson, 1994; Bechara, Tranel, \& Damasio, 2000). It is a well-established method to assess decision making also in studies on substance-use disorder and gambling disorder (e.g., Brevers et al., 2013; Buelow \& Suhr, 2009; Kovács, Richman, Janka, Maraz, \& Andó, 2017). Summarizing empirical findings which are related to social-networks-use disorder (for example "Facebook addiction, "smartphone addiction", excessive social media use", or "social media addiction"), results illustrate that the symptom severity may be related to disadvantageous decision making in the IGT as well as in delay discounting tasks (Delaney, Stein, \& Gruber, 2018; Khoury et al., 2019; Meshi, Elizarova, Bender, \& VerdejoGarcia, 2019; Turel, He, Brevers, \& Bechara, 2018).

Against the background of theoretical approaches (Brand et al., 2016, 2019), it is assumed that the additional confrontation with addiction-related cues and the experience of craving may affect decision making, especially if they are related to a problematic use behavior. To investigate whether the confrontation with addiction-related cues interferes with decision-making, a modified version of the IGT can be used with addiction-related and neutral visual cues being presented on the advantageous/disadvantageous card decks. Previous studies from the field of substance-use disorder and eating disorder showed that the presentation of addiction-related cues affected decision-making behavior in the IGT (Kriegler et al., 2019; Lescher et al., 2020). Regarding behavioral addictions, this effect has been studied 
in individuals with high sexual excitability and in individuals with tendencies towards buying/shopping disorder (Laier, Pawlikowski, \& Brand, 2014; Trotzke, Starcke, Müller, \& Brand, 2019). Results illustrate that higher arousal, cueinduced craving, and symptom severity were related to disadvantageous decision making in a modified IGT, whereby those options that presented addiction-related cues were preferred over the neutral ones even if their choice resulted in a negative outcome (Laier et al., 2014; Trotzke et al., 2019).

\section{Aim of the current study}

Empirical findings outline the relevance of cue-induced craving and dysfunctional decision making in social-networks-use disorder, however, studies investigating the impact of social-networks-related cues on decision making are yet missing. We firstly aim to investigate whether the presentation of social-networks-related cues interferes with decision-making behavior in the IGT. In two modified conditions of the IGT, social-networks-related pictures are presented either on the advantageous decks or on the disadvantageous decks, whereas neutral cues are displayed on the respective other decks. We hypothesize that individuals prefer those options with social-networks-related pictures as they are more rewarding and more attractive compared to neutral cues (Wegmann, Stodt, et al., 2018). Keeping the interaction of affective and cognitive components in predicting symptom severity of a problematic social-networks use in mind, we further assume that who individuals show dysfunctional decision-making when being confronted with social-networks-related cues, they tend to higher tendencies towards a problematic use of social networks. Accordingly, we assume the effect of the cue presentation (i.e., condition) on tendencies towards a socialnetworks-use disorder to be moderated by decision-making performance. In addition, we assume a moderating effect of cue-induced craving.

\section{METHODS}

\section{Participants and procedure}

In the current study, 146 participants (67 male, 79 female) aged between 18 and 38 years $(M=23.95, S D=3.78)$ took part. All participants used social networks and all of them indicated to use WhatsApp with an average usage time of 100.99 minutes per day $(S D=123.04)$, followed by Instagram $(72.60 \% ; M=92.07, S D=89.33$ minutes per day) and Facebook $(53.42 \% ; M=40.79, S D=50.60$ minutes per day). Other applications mentioned were used even less. One hundred-twelve (76.72\%) participants reported a nonproblematic, 20 (13.69\%) participants a problematic, and 14 (9.59\%) participants a pathological use of social networks (see description in Measures section).

The participants were recruited at the University of Duisburg-Essen, Germany. The study was conducted in a laboratory, individual setting, from November 2019 to
February 2020. After instruction, the participants answered questionnaires, performed a cue-reactivity paradigm, to induce craving, and afterwards performed a modified version of the IGT. The participants were randomly assigned to one of two conditions of the IGT. A visual analogue scale was used to assess subjectively experience craving three times: (1) before and (2) after the cue-reactivity paradigm, as well as (3) after the IGT. The two groups differed neither in the distribution of age $(t(144)=-0.02, p=0.984)$ nor in that of gender $\left(\chi^{2}(1)=2.71, p=0.099\right)$. The study took about 45 minutes. Students got credit points for participation.

\section{Measures}

Visual analogue scale for craving assessment. A visual analogue scale was used to assess subjective craving ("How high do you estimate your current urge to use online communication applications, for example, Facebook, Instagram, Twitter, WhatsApp?"). Participants indicated their craving level on a horizontal slider ranging from zero (= "no urge") to 100 (="very strong urge"). The slider was used three times: before (baseline craving) and after the cuereactivity paradigm (post craving) as well as after the IGT (control craving).

Cue-reactivity paradigm. A cue-reactivity paradigm was applied to induce craving towards social-networks use (Wegmann, Ostendorf, \& Brand, 2018). The paradigm consists of twelve randomly shown pictures of hands holding a smartphone that displays chat records through different social networks. Each picture had to be rated regarding valence, arousal, and urge on a five-point Likert scale (from $1=$ "very negative/not at all" to $5=$ "very positive/very"). Presentation ${ }^{\circledR}$ was used for the cue-reactivity paradigm.

Modified version of the Iowa Gambling Task (IGT). A computerized version of the IGT (Bechara et al., 1994; Bechara, Tranel, et al., 2000) was used in a modified version. In the IGT, the participants are asked to choose one of four decks per round. Each decision is followed by visual feedback about the win or loss of virtual money associated with the respective card. The four decks differ in the amounts and frequency of possible wins and losses. Overall, decks A and B are disadvantageous (include very high losses), while decks $\mathrm{C}$ and $\mathrm{D}$ are advantageous (include only small losses). The IGT consists of 100 trails, which can be divided into five blocks of 20 trails each. A net score is calculated as the main variable, which depicts the sum of advantageous over disadvantageous choices $([\mathrm{C}+\mathrm{D}]-[\mathrm{A}+\mathrm{B}])$.

In the current study, the IGT was modified with two sets of pictures presented on the back of the decks (see Fig. 1). Forty different social-networks-related and 40 neutral pictures were used. We used distal cues which, unlike proximal cues, are not directly associated with the addiction-related behavior (Conklin, Robbins, Perkins, Salkeld, \& McClernon, 2008). We thereby ensured that the pictures in the IGT significantly differed from those in the cue-reactivity paradigm but are still related to social networks. As distal cues, 


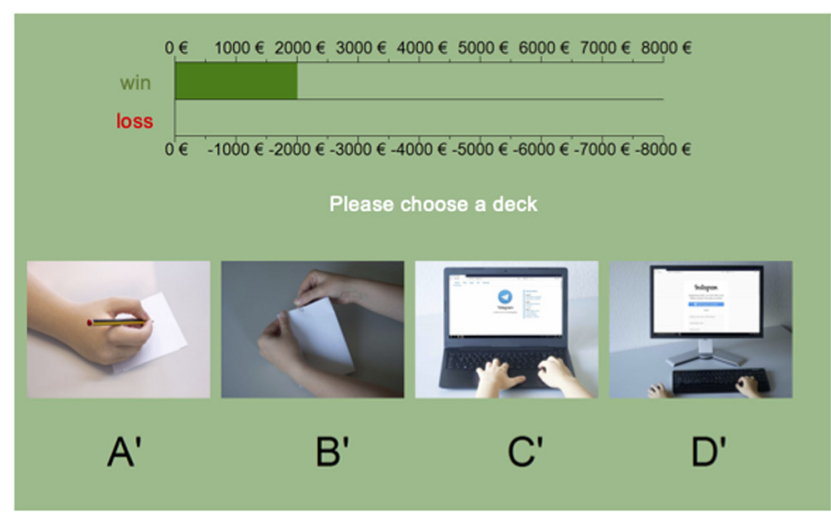

advantageous condition

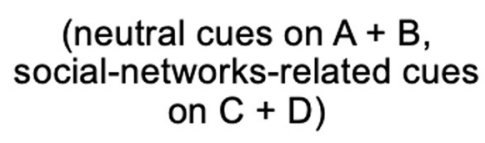

$n=74$

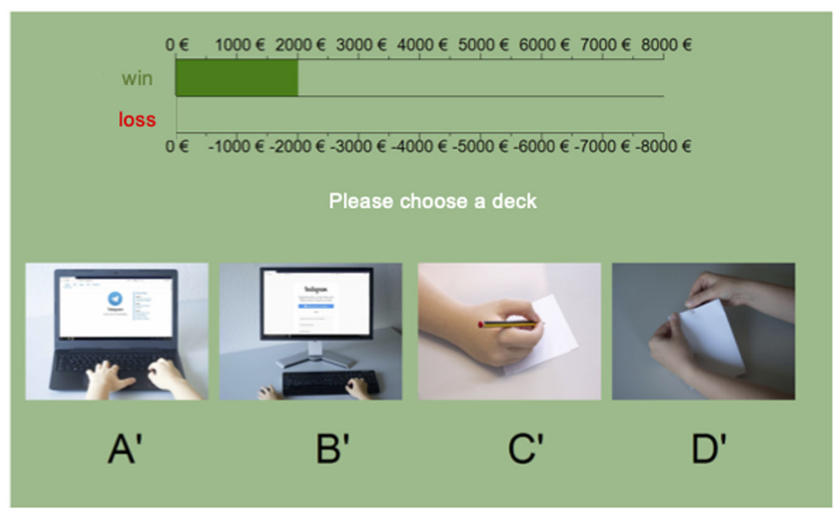

disadvantageous condition

(social-networks-related

cues on $A+B$, neutral cues

on $C+D$ )

$n=72$

Fig. 1. Modified version of the IGT. In the advantageous condition, social-networks-related pictures are presented on the advantageous card decks and neutral pictures are presented on the disadvantageous decks. In the disadvantageous condition, it is vice versa

we used pictures showing a person's hand operating a digital device (smartphone, laptop, desktop computer, tablet) that displays the login page including the logo of a social network on its screen. Each device was combined with the respective login screen of the ten most used social networks in Germany were presented (e.g., Feierabend, Plankenhorn, \& Rathgeb, 2018) resulting in 40 different pictures. Neutral pictures showed a hand holding/using a non-technological item, for example a pen or keys. All pictures were included twice to meet the maximal number of deck choices in the IGT. The presentation sequence was pseudorandomized to ensure that neither the items (neutral pictures) nor the device or social network (social-networks-related pictures) was shown twice in succession. There was no overlap with the pictures of the cue-reactivity paradigm.

We used two different versions of this modified task. In the advantageous condition, social-networks-related pictures were shown on the advantageous decks (C and D) and neutral pictures were shown on the disadvantageous decks ( $\mathrm{A}$ and $\mathrm{B}$ ). In the disadvantageous condition, the pictures were presented vice versa.

Short internet addiction test modified for social-networksuse disorder. Tendencies towards a social-networks-use disorder were assed with the modified version of the short Internet Addiction Test (Wegmann, Stodt, \& Brand, 2015). The questionnaire measures subjective impairments in daily life due to the use of social networks. Participants had to rate twelve items on a five-point Likert scale (from 1= "never" to $5=$ "very often"). The questionnaire consists of two factors each containing of six items: loss of control/time management and craving/social problems. An overall sum score was calculated ranging from twelve to 60 , whereas higher scores indicate higher symptoms of social-networks-use disorder. Sum scores $\geq 31$ indicated a problematic and scores $\geq 38$ indicated a pathological use (Pawlikowski, Altstötter-Gleich, \& Brand, 2013). The internal consistency of the overall sum score was good, Cronbach's Alpha $=0.884$.

\section{Statistical analyses}

Statistical analyses were carried out with SPSS 26.0 (IBM statistics). Group differences in gender distribution were analyzed using $\chi^{2}$-test. $T$-tests for independent samples were used to analyze group differences regarding age and overall decision-making performance. In addition, mixed ANOVAs with Greenhouse Geisser correction were used to analyze within-subject changes in craving experiences (baseline, post, control craving) or in decision-making performance (five blocks of the IGT) under consideration of the IGT condition (between-subjects factor). Multiple hierarchical moderated regression analyses were performed to investigate interaction effects with all predictor variables being centralized (Aiken, West, \& Reno, 1991; Cohen, Cohen, West, \& Aiken, 2003). Significant interaction effects were analyzed by using simple slopes analyses.

\section{Ethics}

The study procedures were carried out in accordance with the Declaration of Helsinki. The local ethics committee approved the study. All participants were informed about the procedure of the study and provided informed consent.

\section{RESULTS}

\section{Description and manipulation check}

The mean values and standard deviations of the questionnaires and the cue-reactivity paradigm are shown in Table 1. 
Table 1. Descriptive statistics of measures of social-networks-use disorder and craving assessment including pairwise comparisons between the two conditions

\begin{tabular}{|c|c|c|c|c|}
\hline & Overall & $\begin{array}{c}\text { advantageous } \\
\text { condition }(n=74)\end{array}$ & $\begin{array}{c}\text { disadvantageous } \\
\text { condition }(n=72)\end{array}$ & \\
\hline & $M(S D)$ & $M(S D)$ & $M(S D)$ & $t$-Test for independent samples \\
\hline sIAT-SNS Overall sum score & $25.59(7.72)$ & $25.24(7.68)$ & $25.94(7.79)$ & $t(144)=-0.57, p=0.548, \mathrm{~d}=0.09$ \\
\hline sIAT-SNS Factor 1 sum score & $15.19(4.65)$ & $14.95(4.57)$ & $15.44(4.75)$ & $t(144)=-0.65, p=0.519, \mathrm{~d}=0.11$ \\
\hline sIAT-SNS Factor 2 sum score & $10.40(3.83)$ & $10.30(3.80)$ & $10.50(3.89)$ & $t(144)=-0.32, p=0.751, \mathrm{~d}=0.05$ \\
\hline VAS baseline craving & $27.25(19.78)$ & $27.95(20.41)$ & $26.54(19.22)$ & $t(144)=0.43, p=0.669, \mathrm{~d}=-0.07$ \\
\hline VAS post craving & $30.25(22.04)$ & $30.19(21.75)$ & $30.31(22.49)$ & $t(144)=-0.03, p=0.975, \mathrm{~d} \leq 0.01$ \\
\hline VAS control craving & $24.12(23.02)$ & $24.50(22.11)$ & $23.72(24.06)$ & $t(144)=0.20, p=0.839, \mathrm{~d}=-0.05$ \\
\hline CR valence rating & $1.80(0.76)$ & $1.85(0.73)$ & $1.75(0.78)$ & $t(144)=0.81, p=0.421, \mathrm{~d}=-0.13$ \\
\hline $\mathrm{CR}$ arousal rating & $2.43(0.72)$ & $2.41(0.70)$ & $2.46(0.75)$ & $t(144)=-0.44, p=0.660, \mathrm{~d}=0.07$ \\
\hline $\mathrm{CR}$ urge rating & $1.60(0.77)$ & $1.61(0.72)$ & $1.60(0.83)$ & $t(144)=0.09, p=0.933, \mathrm{~d}=-0.01$ \\
\hline
\end{tabular}

Notes. sIAT-SNS $=$ short Internet Addiction Test modified for SNS, VAS $=$ visual analogue scale, CR $=$ cue reactivity

No significant differences were observed between the two conditions demonstrating successful randomization. Consistently, the results of the cue-reactivity paradigm also showed no significant differences between the two conditions, which overall demonstrated a successful craving induction. An ANOVA with repeated measures indicated a significant within-subjects effect in craving ratings $(F(1,145)=5.65, p=$ $\left.0.019, \eta_{\mathrm{p}}^{2}=0.037\right)$. The significant increase from baseline to post craving indicates successful induction of subjectively experienced craving (see Fig. 2).

\section{Group differences in IGT performance}

Mean values and standard deviations of the IGT performance are shown in Table 2. We found a significant difference between the two conditions in the overall net score (see Table 2). A two-factorial ANOVA comparing net scores between the two conditions (between factor) and the five blocks (within factor) illustrated a significant effect of the IGT condition $\left(F(1,144)=8.58, p=0.004, \eta_{\mathrm{p}}^{2}=0.056\right)$. The within-effect of the blocks was significant $(F(3.00,144)=$ $\left.11.65, p \leq 0.001, \eta_{\mathrm{p}}^{2}=0.075\right)$ but the interaction effect was not significant $\left(F(3.00,144)=1.25, p=0.291, \eta_{\mathrm{p}}^{2}=0.009\right)$

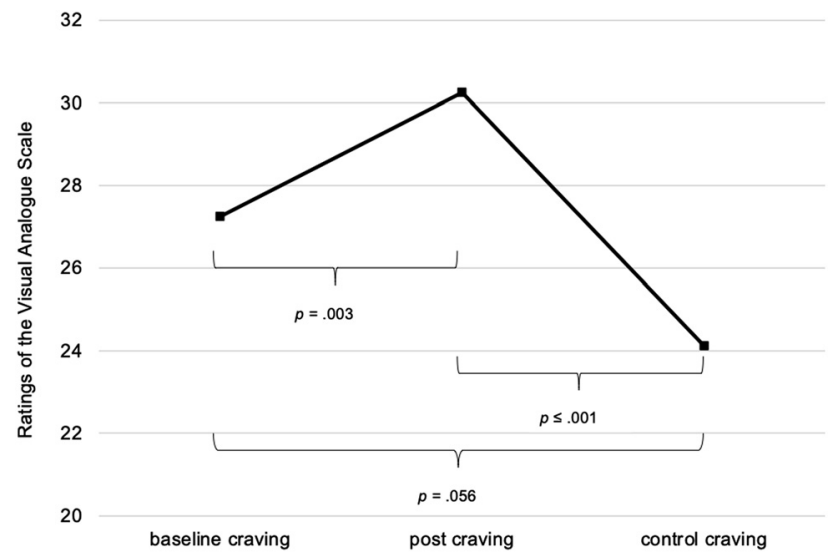

Fig. 2. The figure illustrates the subjective craving responses at the three different times of measurement illustrating IGT-typical curves for both conditions (see Fig. 3). Post-hoc pairwise comparisons demonstrated that participants in the disadvantageous condition, compared to those in the advantageous condition, had significantly higher net scores in blocks 1,3 , and 4 (see Table 2). The block-wise comparisons showed that block 1 net score was significantly lower than those of blocks 2 to 5 (all p's $\leq 0.005$ ) and that block 2 net score significantly differed from block 4 net score ( $p=0.007)$. The post-hoc analysis of the within-effect showed significant differences of the net scores between block 1 and the other four blocks (all p's $\leq 0.042$ ). In the disadvantageous condition of the IGT, significant differences were found between the net scores of block 1 and 3 ( $p=$ $0.001)$ as well as of block 1 and $4(p \leq 0.001)$.

\section{Interaction with decision-making performance and cue-induced craving to predict symptom severity}

In the first analysis, IGT condition, the IGT performance (overall net score), and the interaction term of both were used as predictors. Tendencies towards social-networks-use disorder was used as the dependent variable. The IGT condition $\left(R^{2}=0.002, F=0.30, p=0.585\right)$ and IGT performance $\left(\Delta R^{2}=0.004, \Delta F=0.56, p=0.455\right)$ did not explain a significant amount of variance in social-networksuse disorder, but the interaction did $\left(\Delta R^{2}=0.098, \Delta F=\right.$ $15.46, p \leq 0.001)$. In total, $10.4 \%$ of the variance could be explained $(F(3,142)=5.47, p \leq 0.001)$. The simple-slope analysis emphasizes that individuals with higher tendencies towards a social-networks-use disorder showed a significantly higher net score in the advantageous condition and a lower net score in the disadvantageous condition of the IGT. For individuals with lower tendencies towards a social-networks-use disorder, the decision-making behavior was vice versa; they showed a significantly lower overall net score in the advantageous condition and a higher overall net score in the disadvantageous condition (see Fig. 4).

In the second analysis, we analyzed the additional moderating effect of including cue-induced craving as further moderator variable in predicting problematic social- 
Table 2. Descriptive statistics of the performance in the Iowa Gambling Task (IGT) including pairwise comparison between the two conditions

\begin{tabular}{lcccc}
\hline & Overall & $\begin{array}{c}\text { advantageous } \\
\text { condition }(n=74)\end{array}$ & $\begin{array}{c}\text { disadvantageous } \\
\text { condition }(n=72)\end{array}$ & \\
\cline { 2 - 4 } & $M(S D)$ & $M(S D)$ & $M(S D)$ & $t$-test for independent samples \\
\hline IGT overall net score & $7.48(33.59)$ & $-0.35(34.12)$ & $15.53(31.27)$ & $t(144)=-2.93, p=0.004, \mathrm{~d}=0.49$ \\
IGT block 1 net score & $-2.04(8.88)$ & $-3.92(8.15)$ & $-0.11(9.23)$ & $t(144)=-2.64, p=0.009, \mathrm{~d}=0.44$ \\
IGT block 2 net score & $0.73(9.67)$ & $-0.76(9.92)$ & $2.25(9.23)$ & $t(144)=-1.90, p=0.060, \mathrm{~d}=0.31$ \\
IGT block 3 net score & $2.19(10.86)$ & $-0.22(10.83)$ & $4.67(10.40)$ & $t(144)=-2.78, p=0.006, \mathrm{~d}=0.46$ \\
IGT block 4 net score & $3.44(10.02)$ & $1.81(10.16)$ & $5.11(9.66)$ & $t(144)=-2.01, p=0.046, \mathrm{~d}=0.33$ \\
IGT block 5 net score & $3.16(9.33)$ & $2.73(9.39)$ & $3.61(9.31)$ & $t(144)=-0.57, p=0.570, \mathrm{~d}=0.09$ \\
\hline
\end{tabular}

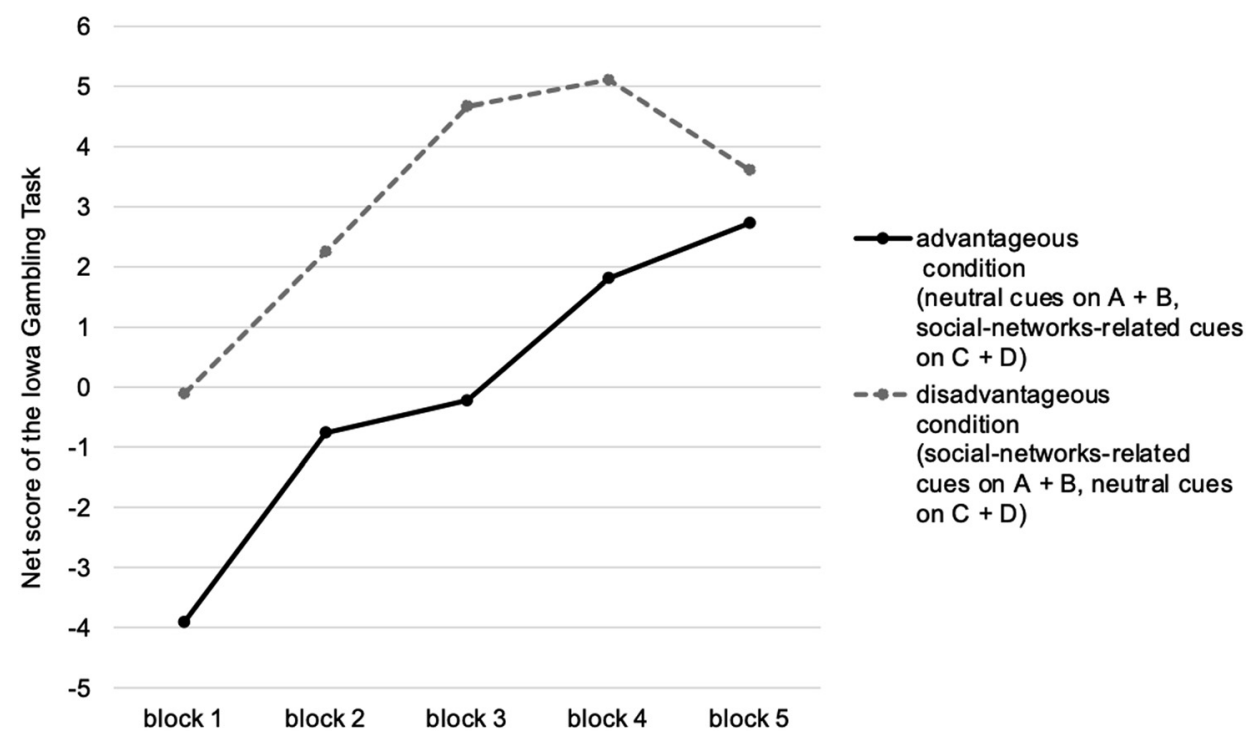

Fig. 3. The figure illustrates the block-wise IGT performance in the two different task conditions. In the advantageous condition, socialnetworks-related pictures were presented on the advantageous card decks and neutral pictures were presented on the disadvantageous decks. In the disadvantageous condition it was vice versa

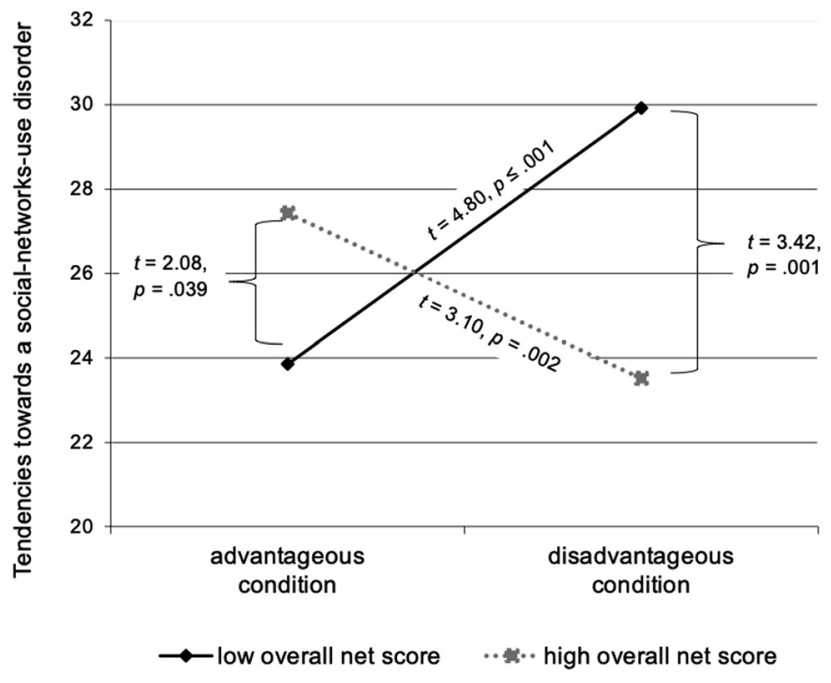

Fig. 4. Simple slopes for interaction effects of IGT condition with the overall net score in the IGT predicting tendencies towards a social-networks-use disorder. Variables were grouped one standard deviation above ("high") and below ("low") the mean values networks use. Therefore, the conditions of the IGT, the overall net score, cue-induced craving, and interaction of all predictors were used to explain tendencies towards a socialnetworks-use disorder. Overall, the final model explained $30.3 \%$ of the variance in social-networks-use disorder $(F(7,138)=8.56, p=0.001)$. Nonetheless, even if the inclusion of cue-induced craving as a predictor had a significant effect on symptom severity $\left(\Delta R^{2}=0.260, \beta=0.465, p\right.$ $\leq 0.001)$ the additional inclusion of the interaction between the decision-making performance and cue-induced craving as well as the 3-way interaction did not explain additional variance (see Table 3 ).

\section{DISCUSSION AND CONCLUSIONS}

The results demonstrate that the additional confrontation of social-networks-related cues interferes with decision making in the IGT. We found significant differences in the IGT performance depending on whether social-networks-related pictures were presented on the advantageous or 
Table 3. Statistics of the coefficients of the moderated regression analyses predicting tendencies towards a social-networks-use disorder

\begin{tabular}{|c|c|c|c|c|c|c|}
\hline & & $B$ & $S E(B)$ & $T$ & $\beta$ & $p$ \\
\hline \multirow[t]{5}{*}{ Model 1} & Predictors & & & & & \\
\hline & IGT condition & 0.54 & 0.629 & 0.85 & 0.070 & 0.396 \\
\hline & Overall net score & -0.02 & 0.019 & -1.13 & -0.092 & 0.262 \\
\hline & 2-way interaction & & & & & \\
\hline & IGT condition $\mathrm{x}$ overall net score & -0.07 & 0.019 & -3.93 & -0.314 & $\leq 0.001$ \\
\hline \multirow[t]{9}{*}{ Model 2} & Predictors & & & & & \\
\hline & IGT condition & 0.53 & 0.585 & 0.91 & 0.069 & 0.363 \\
\hline & Overall net score & -0.02 & 0.017 & -1.26 & -0.096 & 0.210 \\
\hline & post craving & 0.16 & 0.026 & 6.16 & 0.465 & $\leq 0.001$ \\
\hline & 2-way interactions & & & & & \\
\hline & IGT condition $\mathrm{x}$ post craving & $\leq-0.01$ & 0.026 & -0.15 & -0.011 & 0.882 \\
\hline & overall net score $\mathrm{x}$ post craving & $\leq 0.01$ & 0.001 & 0.04 & 0.033 & 0.972 \\
\hline & $\begin{array}{l}\text { IGT condition } \mathrm{x} \text { overall net score } \\
\text { 3-way interaction }\end{array}$ & -0.05 & 0.017 & -2.66 & -0.196 & 0.009 \\
\hline & $\begin{array}{l}\text { IGT condition } \mathrm{x} \text { overall net score } \mathrm{x} \text { post } \\
\text { craving }\end{array}$ & $\leq 0.01$ & 0.001 & -0.21 & -0.015 & 0.838 \\
\hline
\end{tabular}

Notes. IGT = Iowa Gambling Task

disadvantageous options. Furthermore, we found significant interaction effects between the IGT condition and decisionmaking performance in predicting symptom severity of a problematic social-networks use.

The results are different from what we had expected: In the advantageous condition (with social-networks-related pictures on advantageous decks), the participants decided more disadvantageously, as compared to the other condition where the social-networks-related pictures were presented on the disadvantageous decks. This indicates that participants, overall, tended to avoid options with social-networks-related cues even if this resulted in negative outcomes. Nevertheless, the additional confrontation with addiction-related cues seems to interfere with the decision-making behavior. The interaction between IGT condition (i.e. cue presentation) and the decision-making performance demonstrates that the way in which decision making is biased by the presentation of addiction-related cues predicts a significant proportion of variance in tendencies towards social-networks-use disorder. Participants whose performance on the IGT deviates from the average (low performance in the disadvantageous condition) have significantly higher symptoms of a problematic social-networks use. The results, especially when considering the interaction effects, expand previous empirical findings of Meshi et al. (2019) and Khoury et al. (2019) regarding the relevance of dysfunctional decision making in excessive social media users and in individuals with smartphone addiction. Moreover, they could be linked to studies on addictive behaviors that used a modified IGT with addiction-related stimuli as well indicating that individuals with higher sexual excitability or individuals showing pathological buying tendencies preferred options presenting addiction-related cues (Laier et al., 2014; Trotzke et al., 2019). Another consideration that should be taken into account is that some researchers argue that the IGT measures decisions under ambiguity in the first, but decision making under risk in the latter trials (Brand, Recknor, Grabenhorst, \& Bechara, 2007;
He et al., 2010). The relationship between problematic socialnetworks use and decision-making difficulties under ambiguity and under risk should be examined in a differentiated manner in the future. Interestingly, a recent study by Meshi et al. (2020) showed results which seem to be contradictory at first sight indicating a negative association between a problematic social-media use and risk taking in ambiguous situations.

In this study, the decision-making process of individuals with tendencies towards social-networks-use disorder might have been especially influenced by affective responses caused by induced craving and the additional confrontation with addiction-related cues potentially leading to cue reactivity. This assumption is consistent with dual-process approaches assuming an imbalance between affective and cognitive processes in addictive tendencies (Bechara, 2005). For individuals suffering from negative consequences due to a problematic behavior it is assumed that addiction-related cues are perceived as more attractive and rewarding leading to the preference of those short-term rewarding options (Bechara, 2005; Buelow \& Suhr, 2009; Volkow et al., 2012). Brand et al. (2019) emphasize that the interactions between affective and cognitive components are the crucial factor in addictive behaviors. The experience of craving and the dominance of affective responses are assumed to explain why individuals with a problematic social-networks use experience a diminished control over an actually goaldirected, functional behavior focusing on learning from feedback and preferring long-term rewards instead the preference of immediate gratifications over long-term goals (Brand et al., 2019). Future studies should pursue this in order to investigate more clearly whether social-networksuse disorder shows comparable processes and mechanisms to other addictive behaviors.

Interestingly, individuals with lower symptom severities did not show the preference of social-networks-related options. It could be assumed that the attractiveness and 
rewarding character of social-networks-related cues could be different from that of other addiction-related cues. A special characteristic of the current study compared to previous studies from addictive behaviors is that we used distal instead of proximal cues. The cues were not individualized for each participant and the demanding character of the neutral and the social-networks-related pictures could have been evaluated differently. It could be that the neutral pictures focused more attention due to visual variety and have therefore been valued more attractive than the specific cues, especially by individuals with lower symptom severity. Moreover, when comparing the findings with previous studies, Laier et al. (2014) showed explicit pornographic content. Such cues are assumed to display primary rewards which are naturally reinforcing and could therefore be relevant for individuals without any addictive tendencies as well (see Gola, Wordecha, Marchewka, \& Sescousse, 2016; Sescousse, Caldu, Segura, \& Dreher, 2013). Nonetheless, the results of the craving assessments before and after the cuereactivity paradigm confirmed that social-networks-related cues indeed increase craving responses. Wegmann, Stodt, and Brand (2018) discussed that although these cues result in the experience of craving it may not be as strong and long lasting as in other addictive behaviors. Moreover, individuals may not experience a very high urge or deprivation, since the urge to check notifications on the smartphone or what is going on online can be pursued easily and does not have to be postponed for a long time and therefore maybe does not affect or interact with the decision-making behavior (Wegmann, Stodt, \& Brand, 2018).

Several limitations have to be mentioned. Even if the results illustrate that the cues indeed had an effect on the decision-making behavior, further studies are needed to investigate the effect of these specific cues in more detail. This mainly includes validation studies testing the stimuli with regard to visual perception (e.g., brightness, complexity, familiarity). The latter appeared brighter (including the bright computer/tablet screen) than the neutral cues, which could have caused more positive evaluation (Lakens, Fockenberg, Lemmens, Ham, \& Midden, 2013) However, against this bias, participants overall tended to avoid the social-networksrelated cues even if it resulted in disadvantageous outcomes. Future studies need to investigate how the pictures' properties and displayed contents (computer screen, logo, brightness etc.) contribute to the reported interaction effect. The relevance of the highly standardized cues for experiencing cue reactivity and craving in different specific Internet-use disorders needs further investigation, even if first results are promising (see Pekal, Antons, Brandtner, Janezko, \& Brand, 2019). Nevertheless, we highly recommend carrying out studies which compare the impact of distal cues in different addictive behaviors. Moreover, the current study is based on a non-clinical sample; accordingly, no valid conclusions concerning individuals with diagnosed problematic or addictionlike behavior could be drawn. However, since the use of social networks is an omnipresent behavior in daily life and we are able to identify individuals suffering from problems due to the use of social networks, we assume that the overall mechanisms seem to be valid and could be linked to theoretical models of addiction research.

In conclusion, this study expands the current empirical findings on associations between decision-making behavior and problematic use of social networks by pointing at the relevance of interfering cue-induced responses. The results demonstrate that the additional presentation of social-networks-related cues can bias decision making under ambiguity.

Funding sources: No financial support was received for this study.

Authors' contribution: EW organized data collection, conducted the statistical analyses, interpreted the results, and wrote the first draft of the paper. SM and PT aided in data interpretation and writing the manuscript. MB supervised the data interpretation and writing the manuscript. All authors contributed to and have approved the final manuscript.

Conflict of interest: The authors declare no conflict of interest related to this manuscript. MB is member of the COST Action 16207 "European Network for Problematic Usage of the Internet".

Acknowledgments: The work by EW, SM, and MB was carried out in the context of the Research Unit ACSID, FOR2974, funded by the Deutsche Forschungsgemeinschaft (DFG, German Research Foundation) - 411232260. The authors are also grateful to Sebastian Gerstberger and Eileen Knoßalla for helping the data collection.

\section{REFERENCES}

Aiken, L. S., West, S. G., \& Reno, R. R. (1991). Multiple regression: Testing and interpreting interactions (Vol. 1). Newbury Park, CA: Sage Publications.

American Psychiatric Association. (2013). Diagnostic and statistical manual of mental disorders (5th ed.). Washington DC: American Psychiatric Publishing.

Andreassen, C. S. (2015). Online social network site addiction: A comprehensive review. Current Addiction Reports, 2, 175-184. https://doi.org/10.1007/s40429-015-0056-9.

Andreassen, C. S., Billieux, J., Griffiths, M. D., Kuss, D. J., Demetrovics, Z., Mazzoni, E., \& Pallesen, S. (2016). The relationship between addictive use of social media and video games and symptoms of psychiatric disorders: A large-scale cross-sectional study. Psychology of Addictive Behaviors, 30(2), 252-262. https://doi.org/10.1037/adb0000160.

Bechara, A. (2005). Decision making, impulse control and loss of willpower to resist drugs: A neurocognitive perspective. Nature Neuroscience, 8, 1458-1463. https://doi.org/10.1038/nn1584.

Bechara, A., Damasio, H., \& Damasio, A. R. (2000). Emotion, decision making and the orbitofrontal cortex. Cerebral Cortex, 10, 295-307. https://doi.org/10.1093/cercor/10.3.295. 
Bechara, A., Damasio, A. R., Damasio, H., \& Anderson, S. W. (1994). Insensitivity to future consequences following damage to human prefrontal cortex. Cognition, 50, 7-15. https://doi.org/ 10.1016/0010-0277(94)90018-3.

Bechara, A., Tranel, D., \& Damasio, H. (2000). Characterization of the decision-making deficit of patients with ventromedial prefrontal cortex lesions. Brain: A Journal of Neurology, 123, 21892202. https://doi.org/10.1093/brain/123.11.2189.

Boyd, D. M., \& Ellison, N. B. (2007). Social network sites: Definition, history, and scholarship. Journal of Computer-Mediated Communication, 13, 210-230. https://doi.org/10.1111/j.10836101.2007.00393.x.

Brand, M., Labudda, K., \& Markowitsch, H. J. (2006). Neuropsychological correlates of decision-making in ambiguous and risky situations. Neural Networks, 19, 1266-1276. https://doi. org/10.1016/j.neunet.2006.03.001.

Brand, M., Recknor, E. C., Grabenhorst, F., \& Bechara, A. (2007). Decisions under ambiguity and decisions under risk: Correlations with executive functions and comparisons of two different gambling tasks with implicit and explicit rules. Journal of Clinical and Experimental Neuropsychology, 29, 86-99. https:// doi.org/10.1080/13803390500507196.

Brand, M., Rumpf, H.-J., Demetrovics, Z., Müller, A., Stark, R., King, D. L., .. Potenza, M. N. (2020). Which conditions should be considered as disorders in the International Classification of Diseases (ICD-11) designation of "other specified disorders due to addictive behaviors"? Journal of Behavioral Addictions. https://doi.org/10.1556/2006.2020.00035.

Brand, M., Rumpf, H.-J., King, D. L., Potenza, M. N., \& Wegmann, E. (2020). Clarifying terminologies in research on gaming disorder and other addictive behaviors: Distinctions between core symptoms and underlying psychological processes. Current Opinion in Psychology, 36, 49-54. https://doi.org/10.1016/j. copsyc.2020.04.006.

Brand, M., Wegmann, E., Stark, R., Müller, A., Wölfling, K., Robbins, T. W., \& Potenza, M. N. (2019). The Interaction of Person-Affect-Cognition-Execution (I-PACE) model for addictive behaviors: Update, generalization to addictive behaviors beyond Internet-use disorders, and specification of the process character of addictive behaviors. Neuroscience and Biobehavioral Reviews, 104, 1-10. https://doi.org/10.1016/j.neubiorev.2019.06. 032.

Brand, M., Young, K. S., Laier, C., Wölfling, K., \& Potenza, M. N. (2016). Integrating psychological and neurobiological considerations regarding the development and maintenance of specific Internet-use disorders: An Interaction of Person-AffectCognition-Execution (I-PACE) model. Neuroscience and Biobehavioral Reviews, 71, 252-266. https://doi.org/10.1016/j. neubiorev.2016.08.033.

Breiner, M. J., Stritzke, W. G. K., \& Lang, A. R. (1999). Approaching avoidance. A step essential to the understanding of craving. Alcohol Research and Health, 23, 197-206.

Brevers, D., Cleeremans, A., Hermant, C., Tibboel, H., Kornreich, C., Verbanck, P., \& Noël, X. (2013). Implicit gambling attitudes in problem gamblers: Positive but not negative implicit associations. Journal of Behavior Therapy and Experimental Psychiatry, 44, 94-97. https://doi.org/10.1016/j.jbtep.2012.07. 008.

Buelow, M. T., \& Suhr, J. A. (2009). Construct validity of the Iowa Gambling Task. Neuropsychology Review, 19, 102-114. https:// doi.org/10.1007/s11065-009-9083-4.

Carter, B. L., \& Tiffany, S. T. (1999). Meta-analysis of cue-reactivity in addiction research. Addiction, 94, 327-340. https://doi.org/ 10.1046/j.1360-0443.1999.9433273.x.

Cohen, J., Cohen, P., West, S. G., \& Aiken, L. S. (2003). Applied multiple regression/correlation analysis for the behavioral science (3rd ed.). Mahwah, NJ: Lawrence Erlbaum.

Conklin, C. A., Robbins, N., Perkins, K. A., Salkeld, R. P., \& McClernon, F. J. (2008). Proximal versus distal cues to smoke: The effects of environments on smokers' cue-reactivity. Experimental and Clinical Psychopharmacology, 16, 207-214. https://doi.org/10.1037/1064-1297.16.3.207.

Damasio, A. R. (1994). Descartes' error: Emotion, reason, and the human brain. New York: Grosset/Putnam.

Damasio, A. R. (2004). William James and the modern neurobiology of emotion. In D. Evans, \& P. Cruse (Eds.), Emotion, evolution and rationality (pp. 3-14). Oxford.

Delaney, D., Stein, L. A. R., \& Gruber, R. (2018). Facebook addiction and impulsive decision-making. Addiction Research and Theory, 26, 478-486. https://doi.org/10.1080/16066359. 2017.1406482.

Dong, G., \& Potenza, M. N. (2014). A cognitive-behavioral model of Internet gaming disorder: Theoretical underpinnings and clinical implications. Journal of Psychiatric Research, 58, 7-11. https://doi.org/10.1016/j.jpsychires.2014.07.005.

Drummond, D. C. (2001). Theories of drug craving, ancient and modern. Addiction, 96, 33-46. https://doi.org/10.1046/j.13600443.2001.961333.x.

Everitt, B. J., \& Robbins, T. W. (2005). Neural systems of reinforcement for drug addiction: From actions to habits to compulsion. Nature Neuroscience, 8, 1481-1489. https:/doi. org/10.1038/nn1579.

Everitt, B. J., \& Robbins, T. W. (2016). Drug addiction: Updating actions to habits to compulsions ten years on. Annual Review of Psychology, 67, 23-50. https://doi.org/10.1146/annurev-psych122414-033457.

Feierabend, S., Plankenhorn, T., \& Rathgeb, T. (2018). JIM 2018 Jugend, information, (multi-) media. Basisuntersuchung zum medienumgang 12- bis 19-jähriger. In. Stuttgart: Medienpädagogischer Forschungsverband Südwest (LFK, LMK).

Gola, M., Wordecha, M., Marchewka, A., \& Sescousse, G. (2016). Visual sexual stimui - cue or reward? A perspective for interpreting brain imaging findings on human sexual behaviors. Frontiers in Human Neuroscience, 10, 402. https://doi.org/10. 3389/fnhum.2016.00402.

He, Q., Xue, G., Chen, C., Lu, Z., Dong, Q., Lei, X., ... Bechara, A. (2010). Serotonin transporter gene-linked polymorphic region (5-HTTLPR) influences decision making under ambiguity and risk in a large Chinese sample. Neuropharmacology, 59(6), 518526. https://doi.org/10.1016/j.neuropharm.2010.07.008. 
Khoury, J. M., Couto, L. F. S. C., Santos, D. A., Oliveria e Silva, V. H., Drumond, J. P. S., Lopes de Carvalho e Silva, L., ... Duarte Garcia, F. (2019). Bad choices make good stories: The impaired decision-making process and skin conductance response in subjects with smartphone addiction. Frontiers in Psychiatry, 10, 73. https://doi.org/10.3389/fpsyt. 2019.00073.

Kovács, I., Richman, M. J., Janka, Z., Maraz, A., \& Andó, B. (2017). Decision making measured by the Iowa Gambling Task in alcohol use disorder and gambling disorder: A systematic review and meta-analysis. Drug and Alcohol Dependence, 181, 152-161. https://doi.org/10.1016/j.drugalcdep. 2017.09.023.

Kriegler, J., Wegener, S., Richter, F., Scherbaum, N., Brand, M., \& Wegmann, E. (2019). Decision making of individuals with heroin addiction receiving opioid maintenance treatment compared to early abstinent users. Drug and Alcohol Dependence, 205, 107593. https://doi.org/10.1016/j.drugalcdep.2019. 107593.

Kuss, D. J., \& Griffiths, M. D. (2011). Online social networking and addiction: A review of the psychological literature. International Journal of Enviromental Research and Public Health, 8, 35283552. https://doi.org/10.3390/ijerph8093528.

Kuss, D. J., \& Griffiths, M. D. (2017). Social networking sites and addiction: Ten lessons learned. International Journal of Enviromental Research and Public Health, 14, 311-328. https://doi. org/10.3390/ijerph14030311.

Laier, C., Pawlikowski, M., \& Brand, M. (2014). Sexual picture processing interferes with decision-making under ambiguity. Archives of Sexual Behavior, 43, 473-482. https://doi.org/10. 1007/s10508-013-0119-8.

Lakens, D., Fockenberg, D. A., Lemmens, K. P. H., Ham, J., \& Midden, C. J. H. (2013). Brightness differences influence the evaluation of affective pictures. Cognition and Emotion, 27, 1225-1246. https://doi.org/10.1080/02699931.2013.781501.

Leng, Y., He, X., Zhu, B., Li, P., Xiao, C., \& He, W. (2019). The craving and excitement of social networking sites addicts: Based on cue-reactivity. Frontiers in Psychology, 10, 1717. https://doi. org/10.3389/fpsyg.2019.01717.

Lescher, M., Wegmann, E., Müller, S. M., Laskowski, N. M., Wunder, R., Jiménez-Murcia, S., ... Müller, A. (2020). A randomized study of food pictures-influenced decision-making under ambiguity in individuals with morbid obesity. Frontiers in Psychiatry, 11(822). https://doi.org/10.3389/fpsyt.2020. 00822.

Meshi, D., Elizarova, A., Bender, A., \& Verdejo-Garcia, A. (2019). Excessive social media users demonstrate impaired decision making in the Iowa Gambling Task. Journal of Behavioral Addictions, 8, 169-173. https://doi.org/10.1556/2006.7.2018. 138.

Meshi, D., Ulusoy, E., Özdem-Mertens, C., Grady, S. M., Freestone, D. M., Eden, A., \& Ellithorpe, M. E. (2020). Problematic social media use is associated with increased risk-aversion after negative outcomes in the Balloon Analogue Risk Task. Psychology of Addictive Behaviors, 34, 549-555. https://doi.org/10. 1037/adb0000558.
Nadkarni, A., \& Hofmann, S. G. (2012). Why do people use Facebook? Personality and Individual Differences, 52, 243-249. https://doi.org/10.1016/j.paid.2011.11.007.

Pawlikowski, M., Altstötter-Gleich, C., \& Brand, M. (2013). Validation and psychometric properties of a short version of Young's Internet Addiction Test. Computers in Human Behavior, 29, 1212-1223. https://doi.org/10.1016/j.chb.2012.10. 014.

Pekal, J., Antons, S., Brandtner, A., Janezko, J., \& Brand, M. (2019). Cue-reactivity and craving in specific Internet-use disorders: How distal cues affect the urge to use. Paper presented at the International Conference on Behavioral Addictions, Yokohama, Japan.

Sayette, M. A., Shiffman, S., Tiffany, S. T., Niaura, R. S., Martin, C. S., \& Shadel, W. G. (2000). The measurement of drug craving. Addiction, 95, 189-210. https://doi.org/ 10.1080/ 09652140050111762.

Schiebener, J., \& Brand, M. (2015). Decision making under objective risk conditions - a review of cognitive and emotional correlations, strategies, feedback processing, and external influences. Neuropsychology Review, 25, 171-198. https://doi. org/10.1007/s11065-015-9285-x.

Sescousse, G., Caldu, X., Segura, B., \& Dreher, J. C. (2013). Processing of primary and secondary rewards: A quantitative metaanalysis and review of human functional neuroimaging studies. Neuroscience and Biobehavioral Reviews, 37, 681-696. https:// doi.org/10.1016/j.neubiorev.2013.02.002.

Starcke, K., Antons, S., Trotzke, P., \& Brand, M. (2018). Cuereactivity in behavioral addictions: A meta-analysis and methodological considerations. Journal of Behavioral Addictions, 7, 227-238. https://doi.org/10.1556/2006.7.2018.39.

Tiffany, S. T., \& Wray, J. M. (2012). The clinical significance of drug craving. Annals of the New York Academy of Sciences, 1248, 1-17. https://doi.org/10.1111/j.1749-6632.2011.06298.x.

Trotzke, P., Starcke, K., Müller, A., \& Brand, M. (2019). Cueinduced craving and symptoms of online-buying-shopping disorder interfere with performance on the Iowa Gambling Task modified with online-shopping cues. Addictive Behaviors, 96, 82-88. https://doi.org/10.1016/j.addbeh.2019.04.008.

Turel, O., He, Q., Brevers, D., \& Bechara, A. (2018). Delay discounting mediates the association between posterior insular cortex volume and social media addiction symptoms. Cognitive, Affective, and Behavioral Neurscience, 18, 694-704. https://doi. org/10.3758/s13415-018-0597-1.

Volkow, N. D., Wang, G. J., Fowler, J. S., \& Tomasi, D. (2012). Addiction circuitry in the human brain. Annual Review of Pharmacology and Toxicology, 52, 321-336. https://doi.org/10. 1146/annurev-pharmtox-010611-134625.

Wegmann, E., Mueller, S. M., Ostendorf, S., \& Brand, M. (2018). Highlighting Internet-communication disorder as further Internet-use disorder when considering neuroimaging studies. Current Behavioral Neuroscience Reports, 5(4), 295-301. https:// doi.org/10.1007/s40473-018-0164-7.

Wegmann, E., Ostendorf, S., \& Brand, M. (2018). Is it beneficial to use internet-communication for escaping from boredom? Boredom proneness interacts with cue-induced craving and 
avoidance expectancies in explaining symptoms of internetcommunication disorder. PloS One, 13, e0195742. https://doi. org/10.1371/journal.pone.0195742.

Wegmann, E., Stodt, B., \& Brand, M. (2015). Addictive use of social networking sites can be explained by the interaction of Internet use expectancies, Internet literacy, and psychopathological symptoms. Journal of Behavioral Addictions, 4, 155-162. https://doi.org/10.1556/2006.4.2015.021.

Wegmann, E., Stodt, B., \& Brand, M. (2018). Cue-induced craving in Internet-communication disorder using visual and auditory cues in a cue-reactivity paradigm. Addiction Research and Theory, 26, 306-314. https://doi.org/10.1080/16066359.2017.1367385.

Wiers, R. W., Ames, S. L., Hofmann, W., Krank, M., \& Stacy, A. W. (2010). Impulsivity, impulsive and reflective processes and the development of alcohol use and misuse in adolescents and young adults. Frontiers in Psychology, 1, 144. https://doi.org/10. 3389/fpsyg.2010.00144.

World Health Organization. (2019). Website for ICD-11 Beta draft (mortality and morbidity statistics). Retrieved from https://icd. who.int/dev11/1-m/en 